\title{
Reduction of the surface charge of blood polymorphonuclear cells by rheumatoid sera and heat induced aggregated human IgG (HAGG)
}

\author{
K A BROWN.' D McCARTHY. ${ }^{2}$ J D PERRY $?^{3}$ AND D C DUMONDE
}

From the 'Department of Immunology, United Medical and Dental Schools, St Thomas's Campus, London; the 'Department of Biological Sciences, Queen Mary College, London; and the 'Department of Rheumatology, The London Hospital

SUMmARY Cell electrophoresis identifies two main subpopulations of blood polymorphonuclear cells (PMNs), which in terms of the speed of their anodic migration are referred to as the fast and slow population. When blood PMNs from normal healthy subjects were incubated in medium containing $20 \%$ RA serum there was a decrease in the percentage of fast cells with a corresponding increase in the slow population that was directly related to the levels of circulating immune complexes present in the sera. Similar results were obtained when using heat induced aggregated human IgG (HAGG) or Candida albicans instead of RA serum. The 'slowing' effect of HAGG, which was transient and time dependent, appeared to be due to its internalisation by the PMNs. These results suggest that in RA the large number of blood PMNs with a low surface charge (i.e., the slow population) may arise as a result of the constant interaction of these cells with circulating immune complexes.

In the preceding paper cell electrophoresis identified a subpopulation of blood polymorphonuclear cells (PMNs) with a low surface charge that was increased in the blood of patients with rheumatoid arthritis (RA).' The acquisition of a low net negative surface charge may be an inherent property of a subpopulation of PMNs or result from the action of soluble inflammatory factors present in the circulation, as illustrated by the effect of C5a and kallikrein in reducing the electrophoretic mobility (EPM) of PMNs. 2 Although the electrophoretic measurements of rheumatoid PMNs were performed with washed cells and in the absence of serum, 'it is conceivable that soluble blood factors may have reduced the surface charge of a significant proportion of the cells by binding strongly to the membranes and modifying the expression of negatively charged determinants.

To investigate this possibility EPM measurements were undertaken on blood PMNs from normal healthy subjects that had been pretreated with RA sera. From the demonstration that a decrease in

Accepted for publication 28 October 1987.

Correspondence to Dr K A Brown. Department of Immunology. The Rayne Institute. St Thomas's Hospital, London SEI 7EH. surface charge was related to the level of immune complexes present in the sera, additional experiments were performed with heat induced aggregated human IgG (HAGG) instead of RA serum. The lowering of the surface charge by HAGG was shown to be dependent upon its internalisation by the PMNs.

\section{Materials and methods}

CONTROL. AND PATIENTS` SERA

Sera were obtained from 12 normal healthy subjects and 16 patients with classical or definite RA attending the rheumatology department, The London Hospital. Aliquots of the samples were stored at $-70^{\circ} \mathrm{C}$ until use.

SEPARATION OF PMNS

The method was identical to that used in the preceding paper. ${ }^{1}$

CELL ELECTROPHORESIS

A description of this technique is outlined in the preceding paper. ${ }^{1}$ Those PMNs with an EPM of 0.90 $\mu \mathrm{m} . \mathrm{cm} . \mathrm{s}^{-1} \cdot \mathrm{V}^{-1}$ were referred to as the fast population and the remainder collectively termed the slow population. 
MEASUREMENT OF IMMUNE COMPLEXES

Clq binding activity was measured by the method of Zubler et $a l^{3}$ as modified by Casali et $a l^{4}$ This includes the use of Tween 20 to reduce background binding. The mean (SD) binding for 147 normal subjects had previously been shown to be $6(2) \%$. Values above $10 \%$ were considered raised.

PREPARATION OF STABLE HEAT INDUCED AGGREGATED HUMAN IgG (HAGG)

Aggregates of $\mathrm{IgG}$ were prepared as reported previously. ${ }^{5}$ In summary, human IgG (Sigma) was dissolved in borate buffered saline (BBS) at a concentration of $30 \mathrm{mg} / \mathrm{ml}$ and clarified by centrifugation at $5000 \mathrm{rpm}$ for 10 minutes. The supernatant was heated at $60^{\circ} \mathrm{C}$ until the absorbance at 40) $\mathrm{nm}$ reached 0.25 units, and then allowed to stand at $4^{\circ} \mathrm{C}$ for 48 hours. The aggregates were selectively concentrated by polyethylene glycol $(3.5 \%)$ precipitation, washed twice by centrifugation in BBS, and resuspended in $5 \mathrm{ml}$ BBS. The $\mathrm{HAGG}$ was concentrated twofold by air drying in dialysis tubing to give a protein concentration of $2 \mathrm{mg} / \mathrm{ml}$.

INCUBATION OF PMNS WITH HAGG Unless stated otherwise PMNs were incubated with $100 \mu \mathrm{g} / \mathrm{ml} \mathrm{HAGG}$ for 30 minutes at room temperature. Each incubation was terminated by the addition of $20 \mu \mathrm{l}\left(0.1 \mathrm{M}\right.$ iodoacetate $/ 4 \times 10^{6} \mathrm{PMNs}$ to prevent any further internalisation of the aggregates. Treatment of PMNs with iodoacetate alone did not modify their EPM.

PHAGOCYTOSIS OF CANDIDA ALBICANS Candida albicans was maintained on $2 \%$ agar slopes containing $1 \%$ peptone and $2 \%$ glucose. Subcul- tures were made in $1 \%$ peptone and $2 \%$ glucose broth and incubated for three to four days at $28^{\circ} \mathrm{C}$

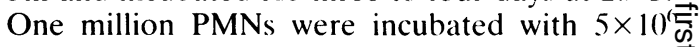
Candida organisms for 30 minutes at $37^{\circ} \mathrm{C}$. Inges tion of the organisms by PMNs was confirmed by previously described radiometric assay."

STATISTICAL ANALYSIS

Statistical analysis of data was performed by Student's $t$ test and linear regression analysis.

\section{Results}

When PMNs were treated with Medium 199 con $\frac{2}{1}$ taining $20 \%$ RA sera for 30 minutes at room temp:erature this often resulted in a decrease in the percentage of cells ascribed to the fast populatione (Fig. 1). The extent of this decrease was directlyo related to an increase in the serum concentration of soluble immune complexes. When blood PMNsz were similarly treated with Medium 199 containing $20 \%$ normal human sera there was no modificationof the EPM.

Experiments were performed to determine if $a^{\infty}$ similar 'slowing' of the fast population could beo induced with HAGG. Fig. 2 shows that in all six experiments HAGG produced a decrease (meano $65 \%$ ) in the fast population. This effect of HAGC0 was rapid in onset, with maximum slowing being seen at 30 minutes' incubation (Fig. 3a). Thereafte $\overrightarrow{\vec{E}}$ extending the duration of incubation resulted in lesహె slowing, so that after five hours and 20 hours the percentage of slow cells in the PMN suspension was? similar to that at the start of the experiment. As shown in Fig. $3 b$ the addition of a fresh concentra? tion of aggregate $(50 \mu \mathrm{g} / \mathrm{ml})$ to PMNs that had

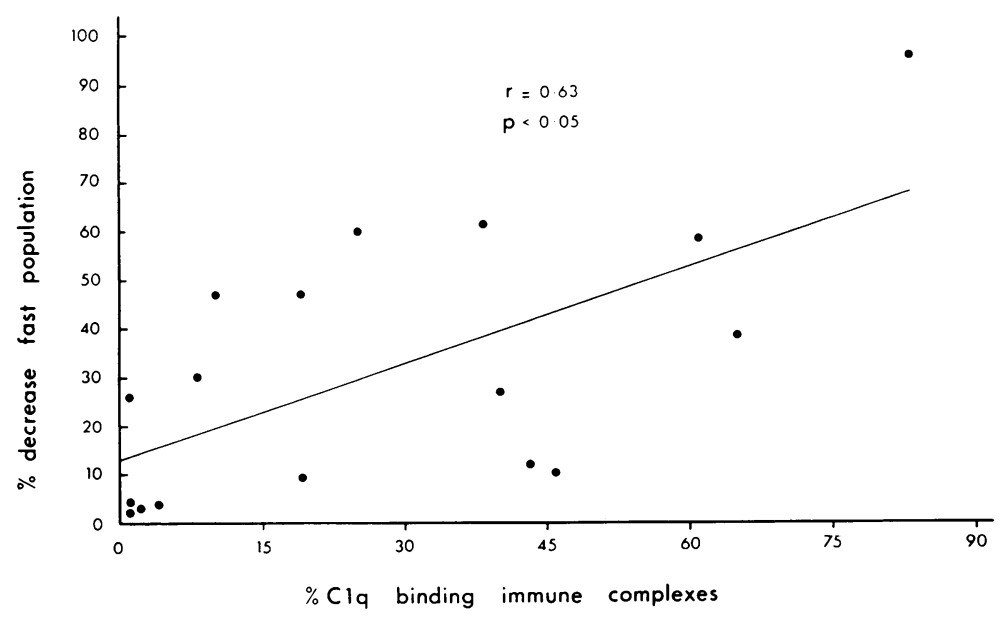

Fig. 1 Incubation of normal blood PMNs in 20\% RA sera resulted in a decrease of the fast population which was related to th level of circulatory immune complexes as measured by the C' la binding assay. Each point represents the responsiveness of PMNs from one subject. 


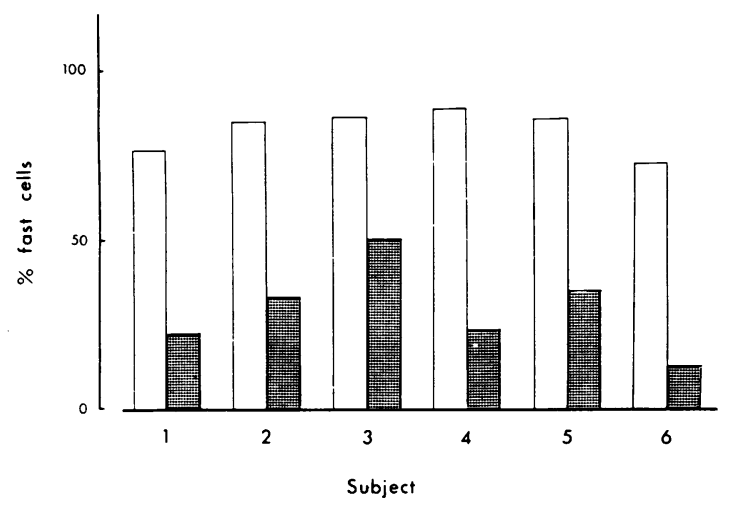

Fig. 2 Effect of HAGG on the distribution of the fast population of blood PMNs from normal subjects. PMNs $\left(1 \times 10^{\circ}\right)$ from six subjects were incubated with $100 \mu \mathrm{g}$ $H A G G$ for 30 minutes. Open blocks represent the percentage of fast cells before experiment and shaded blocks the percentage of fast cells after HAGG.

a. Length of incubation with HAGG

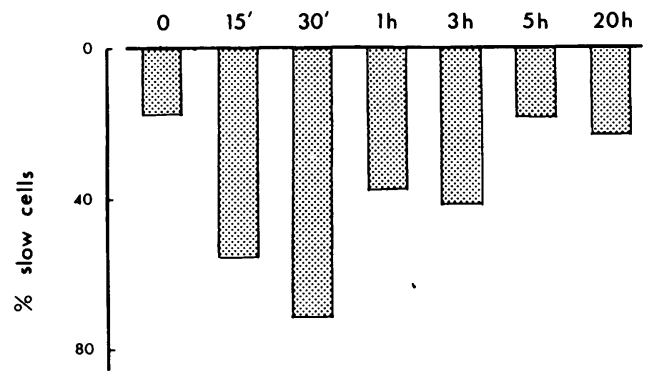

b. Length of incubation with HAGG

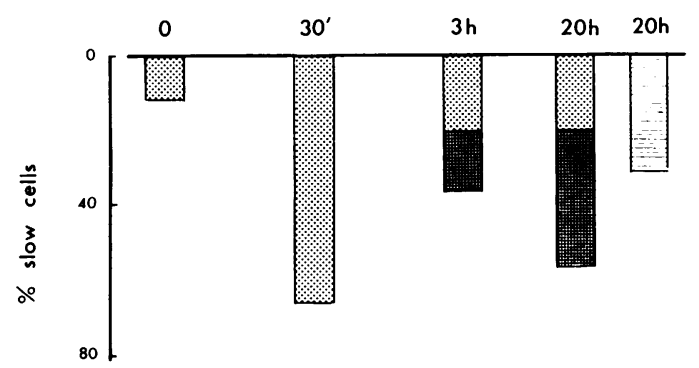

Fig. 3 Time course of the HAGG induced 'slowing' effect of normal blood PMNs. (a) $I \times 10^{\circ}$ PMNs were treated with $100 \mu \mathrm{g} \mathrm{HAGG}$ for the designated times. (b) PMNs that had been incubated with $100 \mu \mathrm{g} \mathrm{HAGG}$ for three or 20 hours were rechallenged with $100 \mu \mathrm{g} \mathrm{HAGG}$ for a further 30 minutes (shaded blocks). The striped block at 20 hours represents the percentage of slow cells in PMNs that had been challenged with $100 \mu \mathrm{g} H A G G$ at 0,3 , and 20 hours. At the end of each incubation PMNs were treated with iodoacetate before EPM measurements. Viability of PMNs was not modified at any stage of the incubation. already been incubated with HAGG for three or 20 hours (and the incubation extended for another 30 min) produced a further increase in the percentage of slow cells, but this did not approach the extent of slowing seen when untreated PMNs were incubated with HAGG for only 30 minutes. Moreover, when PMNs were repeatedly challenged with $\mathrm{HAGG}$ at 0 , 3 , and 20 hours the percentage of slow cells present at the end of culture was not significantly different from the percentage of those PMNs which had been incubated with only one preparation of HAGG for three or 20 hours.

At this stage of the investigation it was not apparent whether the slowing induced by HAGG was due to the aggregates binding to the surface of the PMNs or a consequence of their internalisation. Incubation of HAGG with PMNs that had been pretreated with iodoacetate (to inhibit internalisation of HAGG) did not modify the surface charge of the cells, even though the aggregates were shown by immunofluorescence studies to be firmly bound to the cell surface (data not shown). These results suggest that the HAGG induced decrease in PMN surface charge is due to the internalisation of the aggregate.

To investigate if an increase in the slow population was a general phenomenon of phagocytosis rather than an event specifically related to the internalisation of soluble immune complexes EPM

Table 1 Effect of incubating pre-and post-iodoacetate treated blood PMNs from normal subjects with $H A G G$

Slow cells $(\%)$

\begin{tabular}{lll}
\hline Control & $H A G G+$ iodoacetate & lodoacetate $+H A G G$ \\
\hline $15(5)$ & $58(11)$ & $19(6)$
\end{tabular}

Results are the mean (SD) of three experiments. $1 \times 10^{6}$ PMNs were either incubated with $100 \mu \mathrm{g} \mathrm{HAGG}$ for 30 minutes and then iodoacetate treated, or iodoacetate treated first followed by incubation with HAGG.

$\mathrm{PMNs}=$ polymorphonuclear cells; $\mathrm{HAGG}=$ heat induced aggregated human IgG.

Table 2 Modification of the distribution of the electrophoretic subpopulations of blood PMNs from normal subjects by phagocytosis of Candida albicans

\begin{tabular}{llc}
\hline $\begin{array}{l}\text { Patient } \\
\text { No }\end{array}$ & $\begin{array}{l}\text { \% Fast } \\
\text { population }\end{array}$ & $\begin{array}{c}\% \text { Slow } \\
\text { population }\end{array}$ \\
\hline $1 \quad$ Control & 81 & 15 \\
+ C albicans & 55 & 45 \\
$2 \quad$ Control & 97 & 3 \\
+ C albicans & 75 & 25 \\
$3 \quad$ Control & 97 & 5 \\
+ C albicans & 59 & 41 \\
\hline
\end{tabular}


measurements were performed on PMNs after their phagocytosis of Candida albicans. Table 2 shows that phagocytosis of the yeast produced an increase in the slow population.

\section{Discussion}

Short term incubation of blood PMNs from normal subjects with RA sera resulted in an increase of the slow population to a level similar to that seen in blood PMNs from patients with RA. The extent of this increase was directly related to the concentration of circulating immune complexes in the RA sera. A similar decrease in the surface charge of PMNs occurred after challenge with either HAGG or Candida albicans. The HAGG induced effect appears to result from the internalisation of the aggregates rather than their passive adsorption to the membrane as demonstrated by the failure of HAGG to increase the slow population of PMNs treated with iodoacetate.

As incubation of PMNs with $\operatorname{IgG}$ aggregates $^{7}$ and RA sera containing immune complexes ${ }^{x}$ promotes degranulation, the lowering of the surface charge could arise from the masking of negatively charged groups by the extracellular release of positively charged proteins and ions such as lysozyme and calcium. Alternatively, the internalisation of part of the outer membrane during ingestion to form the phagosome may lead to a temporary loss of those ionogenic groups that determine the electrokinetic behaviour of the cell.

The optimum slowing of normal blood PMNs by HAGG occurred after a 30 minute incubation. Extending the incubation to five hours resulted in the percentage of slow cells returning to its initial value. When HAGG treated PMNs were further challenged with aggregate three and 20 hours after the start of the experiment the increase in the slow cell population was not as great as that seen when fresh PMNs were incubated with HAGG for only 30 minutes. These experiments showed that HAGG induces only a transient reduction of the surface charge, so that the increase in the slow population of blood PMNs from patients with RA described in the preceding paper $^{1}$ may be due to the continuous internalisation of circulating immune complexes.

An important question that arises from the present study is whether a decrease in the net negative surface charge of PMNs reflects an aberrant function. Removal of membrane associated sialic acid is thought to enhance cell adhesion by decreasing the electrostatic repulsive forces, as shown by the increased attachment of neuraminidase treated PMNs to cultured endothelium. ${ }^{9}$ In a recent study we showed that HAGG enhanced the adherence of normal blood PMNs to cultured? endothelium provided that serum was absent from? the culture. "When serum was present the HAGG had an opposite action in that it inhibited adher $=$ ence. Similarly, RA sera induced an inhibition of adhesion; an effect that was directly related to the level of circulating immune complexes. These find $\overrightarrow{\mathrm{D}}$ ings suggest that the HAGG induced enhancemen? of PMN adhesion may well be related to a reductiones in the surface electrostatic barrier that operateso between the negatively charged PMNs and vascularendothelial cells, but when serum is present other factors abrogate this effect. Although a decrease ino electrostatic repulsion may not contribute to the in vitro attachment of PMNs to endothelium of large vessels, it is conceivable that this physical permuta-or tion may have a greater bearing on the marginations of PMNs to microvascular endothelium, such as thato in the joint synovium where the underlying inflammatory lesion may alter the metabolism, phenotype $\overrightarrow{\vec{z}}$ or function of endothelial cells so as to favour the intercedence of physical attractive forces.

Moreover, it is appropriate to consider that the $\overrightarrow{0}$ functional characteristics of PMNs whose surface charge is decreased by the action of soluble immune complexes may be different from those of cellss whose surface charge is reduced after treatment witho neuraminidase. Whereas neuraminidase cleaves气 sialic acid from the cell surface the effect of HAGG禺 may be to alter the expression of other negatively charged groups, such as carboxylate ions or phos-3 pholipids, which also contribute to the cells' topo-? chemistry.

Unstimulated blood PMNs from patients with RA display an enhanced chemiluminescence and nit roblue tetrazolium activity compared with that seen with normal healthy subjects ${ }^{11}$; an increase in the chemiluminescence of PMNs and their increasedo reduction of nitroblue tetrazolium being associated with respiratory burst activity and, by inference, the generation of reactive oxygen species. In a recent $D$ series of experiments we found that the extent of HAGG induced chemiluminescence by PMNs was related to their decrease in EPM (unpublished observations). Thus a reduction in surface charge 0 and the generation of respiratory burst activity byc soluble immune complexes may arise from a com-주 mon perturbation of cell membrane components 6 Leucocyte adhesion functions, such as phagocytosis, $\mathbb{\varnothing}$ margination, and chemotaxis, are dependent upon $\stackrel{?}{?}$ the level of expression of a group of membrane $\underset{T}{0}$ associated glycoproteins referred to as the $\mathrm{CDw} 18 \mathrm{O}$ complex or Mac-1 glycoprotein family. ${ }^{12} 1.3$ The reduction in cell surface charge by inflammatory⿺ factors such as immune complexes may relate to ano alteration in the expression of these adhesion 
molecules that is reflected in subtle changes of cell function. Studies are required to investigate if there is an association between a modification of cell surface charge and the expression of the Mac-1 glycoprotein family and whether the acquisition of a particular cell surface charge by PMNs reflects their functional status.

\section{References}

1 Brown K A. Perry J D P. Black C. Dumonde D C. Identification by cell electrophoresis of a subpopulation of polymorphonuclear cells which is increased in paticnts with rheumatoid arthritis and certain other rheumatological disorders. Ann Rheum Dis 1988: 47: 353-8.

2 Gallin J I. Durocher J R, Kaplan A P. Interaction of leucocyte chemotactic factors with the cell surface. I. Chemotactic factorinduced changes in human granulocyte surface charge. $J$ Clin Invest 1975; 55: 967-74.

3 Zubler R H, Large G T, Lambert P H, Miescher P A. Detection of immune complexes in unheated sera by a modified ${ }^{125} \mathrm{I}-\mathrm{Clq}$ binding test. $J$ Immunol 1976; 116: 232-5.

4 Casali P. Bossus A. Carpenticr N A. Lambar P M. Solid-phase enzyme immunoasay or radioimmunoassay for the detection of immune complexes based on their recognition by conglutinin: conglutinin-binding test. A comparative study with ${ }^{125}$ I-labelled Clq-binding and Raji-cell RIA tests. Clin Exp Immunol 1977; 29: $342-54$.

5 McCarthy D. Goddard D H. Pell B K. Holborow E J. Intrinsically stable IgG aggregates. J Immunol Methods 1981: 41: $63-74$.
6 Bridges C G, Dasilva G L. Yamamura M, Valdimarsson H. A radiometric assay for the combined measurement of phagocytosis and intracellular killing of Candida albicans. Clin Exp Immunol 1980; 42: 226-33.

7 Lucisano Y M. Mantovani B. Lysosomal enzyme release from polymorphonuclear leukocytes induced by immunc complexes of IgM and of IgG. J linimunol 1984: 132: 2015-20.

8 Morrison A D. Prazansky W, Ronadive N S. Relcase of lysosomal enzymes from human polymorphonuclear leukocytes by soluble intermediate immune complexes. Scand J Rheumatol 1978; 7: 241-8.

9 Hoover R L. Briggs R T. Karnovsky M J. The adhesive interaction between polymorphonuclear leucocytes and endothelial cells in vitro. Cell 1978: 14: 423-8.

10) Chasty R C. Brown K A. Shechan N J. et al. Rhcumatoid blood decreases the adherence of polymorphonuclear cells (PMNs) to cultured endothelium. Ann Rheum Dis 1987; 46: 98-103.

11 Wandall $\mathrm{J} \mathrm{H}$. Leucocyte function in paticnts with rheumatoid arthritis: quantitative in-vivo leucocyte mobilisation and in-vitro functions of blood and exudate leucocytes. Ann Rheum Dis 1985: 44: 694-700.

12 Pohlman T H, Stanness K A, Bcatty P G, Ochs H D. Harlan J M. An endothelial cell surface factor(s) induced in vitro by lipopolysaccharide, interleukin 1 , and tumour necrosis factor increases neutrophil adherence by a CDW18-dependent mechanism. J Iminunol 1986; 136: 4548-53.

13 Anderson D C, Miller L J. Schmalsteig F C. Rothlein R. Springer T A. Contributions of the Mac-1 glycoprotein family to adherence-dependent granulocyte functions: structure-function assessments employing subunit-specific monoclonal antibodies. J Immunol 1986: 137: 15-27. 